\title{
Correction to: COVID-19 and Its Global Economic Impact
}

\author{
Zahra Kolahchi, Manlio De Domenico, \\ Lucina Q. Uddin, Valentina Cauda, \\ Igor Grossmann, Lucas Lacasa, Giulia Grancini, \\ Morteza Mahmoudi, and Nima Rezaei (B)
}

\section{Correction to:}

Chapter 46 in: N. Rezaei (ed.), Coronavirus Disease - COVID-19, Advances in Experimental Medicine and Biology 1318, https://doi.org/10.1007/978-3-030-63761-3_46

This book was inadvertently published with incorrect affiliation of Dr. Manlio De Domenico. The affiliation has now been corrected in the chapter. 